\title{
Sylvia Plath and Electracy
}

\author{
Alan Ramón Clinton
}

\section{The Impossible Archive}

Sylvia Plath's short story "Johnny Panic and the Bible of Dreams," written in 1958, reads like an archival fantasy. Its narrator, a secretary in a mental hospital, spends each day "facing the door of the office and [typing] up other people's dreams" (17). In media-technology terms, this task already presents a problem, as dreams operate on the level of the Lacanian imaginary in addition to the symbolic register recorded by the typewriter. The talking (or typing) cure, which attempts to convert dreams into discourse, is, according the media theorist Friedrich Kittler in Gramophone, Film, Typewriter, the final, ultimately futile "attempt to establish writing under media conditions" (90). Hence, the Bible of Dreams can only succeed to the extent that it does not limit itself to bibliographic methods. But then, what is a poet, the archivist who, Plath writes, "must forget the dreamer and remember the dream" (26), to do about this media gap?

The simple answer is that the poet, often figured as a "secretary of dreams" in cultures where writing and print have been the primary mediums of communication, can do nothing about this gap. Rather, I hope to argue that Plath's poetic project, envisioned in "Johnny Panic and the Bible of Dreams" and most fully realized in the Ariel poems (including those poems written at the time of the Ariel compositions but not collected in the volume), involves not, as Kittler argues about Freud, establishing writing under media conditions, but instead bringing writing into media conditions. Whereas secretarial dream poets have either relied on transcendent

Alan Ramón Clinton currently teaches interdisciplinary writing at Northeastern University in Boston. He is the author of Mechanical Occult: Automatism, Modernism, and the Specter of Politics. 
inspiration ("Caedmon's Hymn") or lamented the interference of dream signals (Coleridge's "Kubla Khan”), Plath's later poetry intuits the rhetoric of the digital age. In fact, by drawing on media theorist Gregory Ulmer's definition of "electracy" as a conductive or, as he has also called it, "punceptual" logic which brings different concepts together based on their concrete similarities rather than their abstract connections, one might argue that Plath's Ariel poems are most effectively read as switchboards that privilege neither the historical nor the personal, but instead shift from one register to the other, conductively rather than inductively or deductively, with the result of illuminating both. This argument requires reading the Ariel poems as mediumistic events, but with an emphasis on the technological definitions of the word "medium." The very definition of the word in fact had a technical meaning long before it had a spiritual one, suggesting that even spiritual or poetic mediums are primarily, as originally defined, a matrix for conducting or transporting alien substances.

In reality, the spiritual/poetic and technological definitions of "medium" are not fundamentally opposed. As I have argued in my book Mechanical Occult, spiritualist mediums have always expressed and envisioned their powers in technological terms. ${ }^{1}$ Reading Plath in this manner, however, will further problematize the limiting effects of "confessional" approaches to her work. What sort of confession, after all, can mediums perform? As Helen Sword instructs in Ghostwriting Modernism, the spiritualist medium's enunciations are characterized by "multiple perspectives, fragmented discourse, and simultaneous claims to authority and passivity" (x) rather than the unified subjectivity implied by confessional discourse. Given these properties, the message of the medium is the message as discourse network.

Consequently, "Johnny Panic and the Bible of Dreams" can be read as an "apparatus poetica," a discourse on poetry as an archival technology, rather than the more traditional ars poetica. The story lays out the poetic issues that were already preoccupying Plath and hints at the forms their ultimate articulation might take. As previously mentioned, the story envisions dreams as the medium of the poet, but not in the sense that they are the medium of the analyst:

\begin{abstract}
Dream by dream I am educating myself to become that rare character, rarer, in truth, than any member of the Psychoanalytic Institute, a dream connoisseur. Not a dream-stopper, a dream-explainer, an exploiter of dreams for the crass practical ends of health and happiness, but an unsordid collector of dreams for themselves alone.(17-18)
\end{abstract}

Unfortunately, this connoisseurship involves many practical problems. While the narrator bypasses the reductionist conversion of dreams into medical discourse, she still participates in a process of inscription inimical to the imaginary register in which dreams operate. This process is made even more problematic by its extreme inefficiency. Due to the numerous intrusions characteristic of any clinic, the narrator must "reread what [she] has typed several times, under the pretense of careful proofreading, in order to memorize the dreams" (21). Once committed to memory, these dreams are reinscribed at home in a personal notebook. The narrator is only too aware of the inadequacy of her methodology. 
These problems are exacerbated by the size of the task at hand. Even typing these dreams for eight hours a day, five days a week, the narrator still doesn't "touch a fraction of them the city over" (18). Rather, the world's dreams comprise their own archive without limits. As the narrator dreams about these dreams, they constitute "a great half-transparent lake stretching away in every direction, too big... to see the shores of it, if there are any shores" (19). Interestingly, the narrator's awareness of this endless dream archive can only be realized in a dream of her own, suggesting not only her own interiority with respect to the archive, but also that information can only be properly (without loss of information) archived in its original medium. The limits of this process are realized in "the Borges fable in which the cartographers of the Empire draw up a map so detailed that it ends up covering the territory exactly" (Baudrillard 631). The solution to such analogue dilemmas, as Baudrillard and others point out, is to convert (condense) media into a digital system that can return (reproduce) the analogue data at a later point. With digitality, there are few (if any) limits to the speed and reproducibility of data.

If this formulation seems to place Plath too far ahead of her time, one might look to Walter Benjamin's “The Work of Art in the Age of Mechanical Reproduction” for the necessary qualification. In his discussion of Dadaism, Benjamin suggests that the most innovative arts always seek effects "which could be fully obtained only with a changed technical standard" (237). Just as the Dadaists attempted to achieve the effects of cinema before its possibilities had been fully implemented, so Plath, I would suggest, attempted to achieve the effects of digitality before it became a popular technology. In both of these cases, artists have taken an already existing but not yet developed technology and intuited its future goals. The invention of cinema in 1895 allowed for the sort of practical theorization of the Dadaists twenty years later (and Benjamin's analysis twenty years after that), while Plath's The Colossus was published in 1960, almost equidistant between Alan Turing's famous conceptualization of the universal discrete machine (and Benjamin's essay) and IBM's 1981 introduction of the IBM "PC" or "personal computer."

Indeed, The Colossus bears the same name as the computer Turing built in 1943 to decode German war transmissions, although Turing's machine remained so secret that the American ENIAC (1946) held the undisputed title as the world's first digital computer until the 1970s. Nevertheless, Plath finds herself, in the volume's title poem (CP 129-130), facing a problem similar to the one faced by the narrator of "Johnny Panic and the Bible of Dreams," an archive that can only be properly implemented and accessed via digital means: "I shall never get you put together entirely, / Pieced, glued, and properly jointed." Tellingly, the impossibility of this task is framed in the discourse of craftsmanship. Only the term "jointed" has even the hint of industrialized labor. Turing's COLOSSUS was so named due to the size of the task before it: "The strategic secrets of the Führer's headquarters, Wolfsschanze, could, as is logical, only be cracked by a monster computer" (Kittler, Gramophone 257). The fate of a world war, in other words, could only be entrusted to a device capable of, as Cassius says of Julius Caesar in Shakespeare's play about the emperor, "bestrid[ing] the narrow world / Like a Colossus" (1038). Indeed, only a statue whose legs were reputed to span either side of the harbor at Rhodes could 
provide a fitting name for the machine designed to unite German intelligence with the British Isles. Similarly, Plath's self-appointed task of rebuilding the Colossus is similar in scope to the "Bible of Dreams" commissioned by Johnny Panic, whose last name suggests even more global proportions than the Colossus.

As opposed to Turing's COLOSSUS, which converted encrypted radio frequencies back into intelligible discourse, Plath's malfunctioning Colossus speaks in encrypted radio static: "Mule-bray, pig-grunt and bawdy cackles." Yet, as Kittler notes, "only [complete] nonsense, white noise without information and hence of no use for the upper echelons, provides complete proof against spying" (Gramophone 256). The very fact that the Colossus is a machine guarantees that it can be reassembled, decrypted. Plath is correct in noting that "[i]t would take more than a lightning-stroke / To create such a ruin," for it is electricity itself that allows such a device to operate. As "Mouthpiece of the dead," the Colossus may have reverted to that turn-of-the-century technology, the gramophone, but as a being that operates with "immense skull-plates," it becomes, like Plath herself, an electrically driven cyborg.

\title{
II. A Grounding in Electracy
}

Plath's biography, which one might read as an intensified biography of her age, allows her special access to the issues at stake in the electronic era, including the conductive rhetoric that Ulmer terms "electracy." First, Plath was well aware of Freud and his "Electra Complex," an association no doubt intensified by the actual loss of her father Otto at the age of nine. Her life thus Otto-mated, Plath associates her father with electricity throughout her life. In a short story called "Among the Bumblebees," written near the time of her first shock treatments, ${ }^{2}$ the narrator recounts "Alice" experiencing thunderstorms with her father:

\begin{abstract}
Sitting on her father's lap in the den, watching the waves spray against the sea wall, Alice learned to laugh at the destructive grandeur of the elements. The swollen purple and black clouds broke open with blinding flashes of light, and the thunderclaps made the house shudder to the root of its foundations. But with her father's strong arms around her and the steady reassuring beat of his heart in her ears, Alice believed that he was somehow connected with the miracle of fury beyond the windows, and that through him, she could face the doomsday of the world in perfect safety. (264)
\end{abstract}

And yet, despite (or because of) her father's connective properties, Otto is also deeply associated with disconnection. Weeks before Otto's death, his advanced diabetes required that his leg be amputated. Plath, literalizing Lacan's metaphor, founds her subjectivity with a cut and the subsequent attempts to overcome it. Nevertheless, overcoming such a disconnection is a task more impossible than recording the world's dreams or rebuilding the Colossus, one whose fulfillment can only be imagined as a high-tech form of surgery.

Given these parameters, it would be hard to overestimate the unintended psychological effects that electroshock therapy exerted upon Plath's imagination. Plath's 
biographer Paul Alexander describes the "day's routine" as follows:

Metal probes were placed on Sylvia's temples so that powerful dosages of electricity - "shocks" - could be shot through her body. ...In later years, standard medical procedure would demand that doctors administer electroshock therapy only after the patient was given a muscle relaxant and a general anesthetic. Also, a doctor or nurse would stay with the patient during the recovery period, to provide support and counseling. In the case of Sylvia Plath, none of this happened. Because she had taken no muscle relaxant, her body was rigid with fear. Because she had received no anesthesia, she was, in effect, nearly electrocuted.(119-120)

The intensity of this trauma, which led to her first suicide attempt, would forever rewire Plath's sense of human identity. This rewiring was the result and simultaneously more intense form of a general shift in attitude that had begun over fifty years before. In his book Discourse Networks, Kittler reminds us that, by the end of the nineteenth-century, psychiatrists almost universally described the brain as "a network of telegraphic 'relay stations' with more or less prompt connections" (279). Indeed, it was this concept that led to the invention of shock therapy in the first place. Still, there is a big difference between absorbing a cultural epistemology and having one's "psyche ripped open by [the] raw wattage" (Alexander 120) of an idea, and it is this latter form of embodied rhetoric which, in addition to her poetic abilities, places Plath in a unique cultural position.

These various material, linguistic, and epistemological encounters with electricity allow Plath access to a certain form of thought that Greg Ulmer defines as "electracy." Electrate thought, characteristic of the post-McLuhan era, privileges conductive (as opposed to inductive or deductive) procedures more characteristic of dreamwork and poetry than traditional logic. As opposed to the hierarchy of concepts that argumentative rhetoric demands, electracy organizes ideas based upon distributed networks of concrete similarities - the emphasis is on connection rather than abstraction (1-10). The uncanny tendency of keywords, when typed into search engines, to bring forth widely divergent topics, provides an example of how computers operate according to a set of procedures that in another setting might be called a "playful use of language." But computers do not play in the traditional sense, unless one defines play as a merciless application of concrete poetics.

What's at stake in wedding Sylvia Plath's poetics to electronic logic and the development of computer technology? Not only will it further contribute to the waning prestige of confessional approaches to Plath, which tend to marginalize her cosmopolitan concerns and reiterate the ideology of separate spheres on the level of literature and criticism, but it also complicates our sense of the relationships between historical references and the personal and lyric agendas in Plath's writing. On a broader level, the alliance of poetic and digital logics described by Ulmer and evinced by Plath will necessitate a reevaluation of poetry's relationship to other genres (such as the analytical essay) that are traditionally considered more "critical" in nature. Perhaps an understanding of digital technology and the decentered, 
networked structures of global power arising from it will require that we all become connoisseurs of poetry's ability to make unexpected connections, where its conductive logic operating within media conditions will help us navigate the hidden structures animating the ever-expanding archive of the spectacle.

\section{Electracy and Ethics}

In a controversial article entitled "The Sweatshop Sublime," Bruce Robbins frankly addresses the difficulties Marxist scholars have not only with the recognition of globalism's complexities but with strategizing meaningful action when the structures of injustice are recognized:

$[\mathrm{C}]$ ontemplating the obscure infinity of the social whole ... making us sense that we possess transcendent powers (albeit powers exercised on our behalf and in this case without our active will) yet finally letting us "sink back into ourselves," so that we fail to express those powers in any potentially risky, disobedient action, I suggest that we provisionally call this trope, with a certain inevitable discomfort, the sweatshop sublime. (85)

Those things that make "disobedient action" seem impossible or, even worse, futile, are well-known to Marxist scholars. First, globalism not only appears to us as an "obscure infinity," but multinational corporations and nation-states deliberately obscure the means by which they operate, effectively (they hope) closing off their archives to antagonistic investigators. The second source of futility comes from the role of the scholar as investigator in the first place, which places him or her in a position of limited individual power, often lacking the means or even the knowledge of how to form viable collectives of "praxis." What disturbed many readers of this article seems to me not the first element of the "sweatshop sublime," which hinges on the formidability of one's opponents, but the latter suggestion that part of this formidable nature lies in everyone's (including Marxist scholars') default position as an individual in the capitalist global economy. ${ }^{3}$ Sensitive to charges that they are lacking in "commitment," such scholars are unable to acknowledge the negative dialectics in Robbins' method, designed not to "out" Marxists for tenure but to describe a basic difficulty with which the committed intellectual must always struggle.

In effect, contemporary scholars of globalism find themselves in a position similar to that of the narrator of "Johnny Panic and the Bible of Dreams" - working on a colossal task with inadequate means. A similar sense of inadequacy must have haunted Plath in the isolated London apartment where she wrote the bulk of the Ariel poems. Alone, cut off from the outside world to an extent that must have reinvoked her relationship to her father, Plath began to write poems whose connections between the individual and the global is more vexed than one might expect from someone in her situation. And yet this is precisely why a reappraisal of Plath's poetics, in the context of Marxist theory and Gregory Ulmer's theory of electracy, could prove instructive.

Why, for instance, did Plath choose to name what was to be her final volume Ariel? No doubt Ariel's association with magical speed fascinated Plath, as it did 
the makers of the contemporary communications satellite also named Ariel. In addition, the Shakespearian Ariel's poignant relationship to imprisonment/ noncommunication and servitude (reinforced by the satellite's interrupted transmissions due to U.S. bomb testing) must have influenced Plath. Undoubtedly Plath saw herself, to some extent, playing Ariel to Ted Hughes's Prospero, a relationship which acknowledges Hughes's public power but also her own superior moral (and perhaps poetic) position. But ultimately, moral arguments must pale in comparison to the fantasy of speed itself, intoxicating in its own right but also appealing to someone who felt time to be of the essence, whether stemming from suicidal foreknowledge or, more likely, the brutal existence of a single mother attempting also to be a creative individual. A brief glance at the dates of the Ariel poems will clue in the casual reader to the speed with which they were written. Several critics, most notably A. Alvarez and Timothy Materer, from whom I depart only in my technological inflection of mediumship, have mystified Plath's bipolar tendencies in such a way as to suggest that the Ariel poems were written in an almost medium-like state. As previously noted, the emergent media at the time of Plath's composition beg the question to what extent electric, even electronic, speed informs Plath's volume, not only thematically but in its deep structure as well. Robin Peel, for instance, writes, in yet another defense of Plath's use of Holocaust imagery, that "what the existence of another contemporary meaning of Ariel, that of a communications satellite damaged by nuclear radiation, allows us to consider is the possibility that this poem ["Ariel "] has a contemporary association that has gone unremarked" (182). But what Peel fails to remark is that such associations are in fact at the heart of the question of how the individual can begin to remark on political matters in the first place, connect to them in a way that, by operating outside ethics (what ethics does a machine have, or one who writes like a machine?), creates the conditions in which ethics are possible.

Do the Ariel poems then suggest means by which one may, if not bestride the globe, at least make sorties across the chasm between global realities and individual situatedness? Take, for instance, the notorious "Daddy" (CP 222-4), a poem which more than any other has been the instance of virtuosity, and embarrassment, necessitating defenses of a poet who would use imagery of the Holocaust to depict her personal problems. On some level, every critic acknowledges this is what Plath is doing here. To do otherwise would strain the limits of credibility. From here, one can dismiss Plath as a histrionic bourgeois confessionalist, excuse her metaphors as the products of a truly troubled, even depersonalized mind, or laud Plath as having the courage to address taboo yet politically urgent subject matter. All these arguments, as I've suggested, are ethical in nature and as such, to some extent, posit (usually unconsciously) Plath as an individual subject making choices as to how she will represent herself, how she will confess. But is that what "Daddy," or the "medium-like" poems of Ariel as a whole, are really doing?

Although the poem's title would seem to suggest a confessional, family-romance type poem, the first stanza begins by rejecting this genre as nothing more than a fairy tale:

You do not do, you do not do

Any more, black shoe 
In which I have lived like a foot

For thirty years, poor and white,

Barely daring to breath or Achoo.

It is from this stifling, pedestrian situation that the poem wants to escape. Thus, we are witnessing a flight from the personal to history, terms which, we will soon see, become irrelevant to the electronic logic, if not the ethical effects, of Plath's mediumistic poetry. In an explosive sneeze, an "Achoo," we are transported to another context, "Ach, du," a pun that is unmotivated except from the standpoint of sound, coincidental, allowing the poem to open out onto history, the Holocaust. What is most interesting here is that Plath seems to have constructed a machine for moving between various spheres that are normally considered to have no relationship to one another. It works by being formalistic, encourages connectivity by working on the level of the concrete rather than the abstract, an unpredictable conductivity which is utopian in its promise of a method for overcoming Robbins's "sweatshop sublime," that feeling of being overwhelmed in the face of globality. In this way, the poetic energy of personal suffering is reinforced by the pathos of suffering on a larger scale and vice versa. What Ulmer has termed a "relay system," operating on the basis of linguistic coincidence, makes questions of personal motivation or "the right to speak" seem less urgent in comparison to the highly politicized interpretive methods suggested by the Ariel poems. If Plath's methods are taken seriously by Marxist critics, the question of personal commitment is ameliorated by the possibility that, starting from the most isolated of positions, one can "chance upon" answers to questions presented by our global economy-that is, as long as one entertains the idea that the critic of the future must add poetic methods to her analytical repertoire.

In fact, Ulmer stresses how poetic thought, a natural accomplice to digital logic, is key to overcoming the separation of spheres that plagues all individuals living in a capitalist society which discourages integrating seemingly random events into a more total understanding (and thwarting) of alienation: "The wide image [or puncept] is revealed in this illumination as a pattern that repeats across the discourses... a cognitive map of its maker's "psychogeography" (81). In his use of the terms "cognitive map" and "pyschogeography," Ulmer reveals his indebtedness to the ideas and Marxist goals of Fredric Jameson and the Situationists. In his concept of a "wide image" that "repeats" a "pattern," Ulmer implies that contemporary Marxist thought must occur in the context of poetic practice as theorized by Jacques Derrida in his notion of grammatology. Derrida, in fact, starting with Of Grammatology's discussion of "writing beyond the line," has repeatedly acknowledged his theory's indebtedness not only to literature but to the shifts in cognition resulting from the transition(s) between print culture and electronic culture. That Plath's writing occurs contemporaneously with these shifts, that she lived simultaneously parallel to, through, and in advance of electracy, makes a general mediumistic rereading of her poetry all the more compelling.

In this rereading, Plath's father returns as the Colossus, a "[g]hastly statue with one gray toe / Big as a Frisco seal," but this time Plath seems to have derived the 
equipment (Ariel as communications satellite) if not to crack her father's code, then to perform an even greater feat in learning how to deterritorialize it. Plath/Ariel cannot locate the father because the name of his hometown "is common." A friend reveals "there are a dozen or two." The resulting dissemination forecasts Derrida's famous method of using the common nouns in authors' "proper" names (Genet as "broomflower," Ponge as "sponge") as a means of finding "signatures" which may or may not have been intentionally left in their respective writings. In keeping with this drift towards commonality, Ariel /Plath "thought every German was you" and "the language obscene" in a sense that does not reduce the multiplicity of the Latin $o b{ }^{4}$ Rather, it is a language that works against the "scene" in all its enclosed senses, a language which the poem calls "An engine, an engine / Chuffing me off like a Jew." These lines do not bring the Holocaust to Plath, but Ariel towards the Holocaust, although the linguistic engine being used, unlike the trains on their way to the death camps, is reversible, travels in both directions at once, a train moving at the behest of a "conductor" which, in this case, is not an individual but a means of electronic travel.

Such an engine, simultaneously poetic and electric, operating outside of ethics, in fact lays the groundwork for the ethical move par excellence, traveling beyond the self toward the other, which is always also a traveling from an other to a self. It neither trivializes the suffering of the individual (Plath) nor the tragedy of the group (the European Jews who were, of course, always individuals whose suffering mattered because they were individuals), but allows for communication between the two. Plath's great discovery as a poet was this mechanization of empathy, pathological as it may or may not have been, Electra-cal and electric in a manner anticipating the electronic logic Ulmer has chosen to call "electracy." Therefore, one who reads Plath as primarily a confessional poet, or even merely "a poet" rather than the "modest recording instrument" which André Breton presciently held out as the ideal toward which a poet must strive (123), inevitably fails to recognize that Plath's true significance, her truest humanity, lies in her ability to become, in the Ariel poems, a modest conducting instrument far more deserving of the Shakespearian (and Hebrew ${ }^{5}$ ) name than a communications satellite created by engineers rather than conductors. In reading poems like "Daddy," whatever the motive, in means that privilege the individual, where so-called external references always radiate back towards the nuclear family romance, we become the nuclear radiation that damages the Ariel poems in their function as a satellite communicating empathic, politically charged message.

\section{Conducting the Satellite}

Plath's poetry, therefore, not only develops what Ulmer calls an "electrate" rhetoric but, in poems like "Daddy," teaches us how to read it in alternative ways. A poem like "Burning the Letters" (CP 204-5), written in August of 1962, thereby evinces an exhilaration whose interest extends beyond Plath's relationship to Ted Hughes:

A red burst and a cry

That splits from its ripped bag and does not stop

With the dead eye

And the stuffed expression, but goes on

Dyeing the air, 
Telling the particles of the clouds, the leaves, the water

What immortality is. That it is immortal.

The message of the burning letters is tautological, but their powers of transportation are astounding, more aligned with the communicational speed of Ariel, with digital instantaneity, than with a more traditional literate rhetoric. Then comes October 1962 and the famous "Bee Poems," where the exhilaration of the electronic "buzz" turns, momentarily, to fear:

How can I let them out?

It is the noise that appalls me most of all,

The unintelligible syllables.

It is like a Roman mob,

Small, taken one by one, but my god, together. (CP 213)

In "The Arrival of the Bee Box," the speaker ultimately decides to set the bees free, ostensibly to calm her fears, but perhaps unconsciously allowing the "unintelligible syllables" to disperse, like encrypted ethical pollen, throughout Plath's future poems and poetic method. By the time Plath arrives at "Daddy" eight days later, her "weird luck" (223) could also be read as "wired" luck. The Colossus, however, burdened with remnants of the bourgeois lyric "I," is left broken in favor of the disseminated, disobedient signals carried by Roman, Gypsy, Jew, or bee satellites. The critic who follows these phonetic rewirings in more and more unpredictable directions has begun to read Plath's Ariel period as she herself was reading it, conducting a panic dream archive in a manner more in line with Kittler's update of Freudian and Marxist hermeneutics than with traditional semiotics. In this impossible yet navigable archive, one rewires Lacan's famous formulation to read, "The global is structured like a cybernetic language."

Hence, we hear it in "Fever 103" (CP 231-232) when "[ $\mathrm{t}$ ] he tinder cries" even as we explore the visual and conceptual possibilities when "tinder" and "tender" are linked. In this system of punceptual connectivity, the radiating heat of a fever becomes "Radiation... // Greasing the bodies of adulterers / Like Hiroshima ash and eating in." This simile, in its absurd connection of adultery and the victims of Hiroshima, foregrounds the often arbitrary and labyrinthine moral justifications for murder. It is a self-justifying, domesticated logic, "eating in" rather than "radiating out" in the syllabic flight Plath has discovered. One must reach Hiroshima because it stands alongside the Shoah in the outer limits of human capacity for destruction, and it is necessary to understand the individual logics that lead there. One way of achieving these moments of insight and empathy, the beginnings of more complete understandings and interventions, is to open the "box of maniacs" (CP 213) and allow their "unintelligible syllables" to land on unlikely flowers, perhaps those popping from the grave of "Lady Lazarus" (CP 244-47), the controversial poem defended on grounds of its foregrounded performativity (Strangeways 385). In this latter poem, however, we have a speaker - and hopefully a reader - who is less a woman, even a performing Lazarus, than a network assembled for our consideration, "a million filaments" conducting the personal life, history, ideology, "the strip 
tease" of spectacle, the "trash," the "Flesh, bone," the "wedding ring." When this network claims, "I am your opus," an electrate reader should take this as a challenge, which Plath's oeuvre has at this moment become. What do we make of such indecent, ob-scene poetry? How do we complete/extend the circuit? As deliberately incomplete extensions into the world, Plath's later poems teach us to truly communicate with them, not as judges or litigators but as empathic relays in the spirit of Plath's proclamation that "It is a heart / This holocaust I walk in" (CP 257).

\section{Notes}

${ }^{1}$ The case of one of the most famous Victorian mediums and the psychiatrist who wrote a study of her entitled From India to the Planet Mars is to the point here:

[Hélène] Smith's psychic automatism (and [Théodore] Flournoy's depiction of it) also evinces the modernist fascination with automation. In the preface to his study, Flournoy laments that the French equivalent of the English term "automatist" has not gained general acceptance, and that he must consequently retain the more spiritually connotative "medium" in his exposition (7).... Etymologically speaking, Flournoy has no need to worry about his chosen terminology. The technological use of the word "medium" precedes its spiritual use by over 200 years. The "dominant" spiritual meaning of the word does not appear in print until 10 years after the invention of photography. As for Smith herself, her "triple mediumship: visual, auditive, and typtological" (9) corresponds to each major 'medium' at the turn of the centuryfilm, gramophone, and typewriter....Conversely, the media that Smith simulated are ghostly in their own right..... even the ancient technology of writing has its own god, Thoth, who was a prototype of Hermes and the intimate relationship between all things technical and spiritual. The oldest surviving depiction of a print shop takes the form of a danse macabre; telegraphy leads to table rapping and other connections to the beyond; photography leads to spirit photos; telephones, radio, and sound recordings lead to spirit voices. (Clinton 11-12)

${ }^{2}$ As dated by the Lilly Library.

${ }^{3}$ This is my "psychoanalytic" deduction from the somewhat vituperative letters concerning the article in PMLA's subsequent issue.

${ }^{4}$ According to the Oxford English Dictionary, the Latin preposition is spatial term that is spatially indeterminate, which can mean, among other things, "in the direction of, towards, [or] against."

${ }^{5}$ Ariel, in Hebrew, can alternately designate "altar," "lion of God," and "Jerusalem."

\section{Works Cited}

Alexander, Paul. Rough Magic. New York: Viking, 1991.

Baudrillard, Jean. "Simulacra and Simulation." Postmodern American Fiction. Ed.

Gey, Leebron, and Levy. New York: Norton, 1998.631-7.

Benjamin, Walter. Illuminations. Trans. Harry Zohn. New York: Shocken, 1969. 
Breton, André. What is Surrealism? Ed. Franklin Rosemont. New York: Pathfinder, 1978.

Clinton, Alan. Mechanical Occult: Automatism, Modernism, and the Specter of Politics. New York: Peter Lang, 2004.

Derrida, Jacques. Of Grammatology. Trans. Gayatri Spivak. Baltimore: Johns Hopkins UP, 1976.

Flournoy, Théodore. From India to the Planet Mars: A Case of Multiple Personality with Imaginary Languages. Trans. Daniel B. Vermilye. Princeton: Princeton UP, 1994.

Kittler, Friedrich. Discourse Networks. Trans. Michael Metteer. Stanford: Stanford UP, 1990.

- - . Gramophone, Film, Typewriter. Trans. Geoffrey Winthrop-Young and Michael Wutz. Stanford: Stanford UP, 1999.

Peel, Robin. Writing Back: Sylvia Plath and Cold War Politics. Madison: Fairleigh Dickinson University P, 2002.

Plath, Sylvia. The Collected Poems. Ed. Ted Hughes. New York: Harper and Row, 1981.

- - Johnny Panic and the Bible of Dreams and other prose writings. Ed. Ted Hughes. London: Faber and Faber, 1979.

Robbins, Bruce. "The Sweatshop Sublime." PMLA 117.1 (2002): 84-97.

Shakespeare, William. The Complete Works. Ed. David Bevington. London: Scott, Foresman and Company, 1980.

Strangeways, Al. "'The Boot in the Face': The Problem of the Holocaust in the Poetry of Sylvia Plath." Contemporary Literature 37.3 (1996): 370-391.

Sword, Helen. Ghostwriting Modernism. Ithaca: Cornell University P, 2002.

Ulmer, Gregory. Internet Invention: From Literacy to Electracy. New York: Longman, 2003. 